\title{
Research on improving the innovative ability for college students of applied engineering specialty
}

\author{
Jinshuo Mei ${ }^{1}$, a , Chang Shu² \\ ${ }^{1}$ Applied Science School, Harbin University of Science and Technology, Harbin, 150080, China. \\ ${ }^{2}$ Technical School, Harbin University, Harbin, 150086, China. \\ ameijinshuo@126.com
}

\begin{abstract}
The cultivation of innovation ability has become an important index to measure the quality of current applied engineering specialty. In the current serious employment situation, how to deepen the school-enterprise cooperation, share both resources, innovative training methods, fully mobilize students' autonomous learning ability and cultivate innovative talents which meet the needs of the enterprise, is the current urgent need to solve problem for local university, it is also the key factor which influences the success of reforming cultivation mode of applied engineering specialty in the new situation.
\end{abstract}

Keywords: Applied Engineering Specialty; Innovative Ability; Cooperation between School and Enterprise; Employment Ability

\section{应用型工科专业大学生创新能力培养研究}

梅金硕 ${ }^{1}$, 舒昌 ${ }^{2}$

1. 哈尔滨理工大学应用科学学院, 哈尔滨, 黑龙江, 中国

2. 哈尔滨学院工学院, 哈尔滨, 黑龙江, 中国

摘要: 创新能力的培养已经成为衡量当前应用型工科专业办学质量的重要指标, 在当前严峻 的就业形势下，如何深化校企合作，资源共享，创新培养方式，充分调动学生的自主能力, 培养符合企业所需的创新型人才, 是当前地方本科院校应用型专业急需解决的问题, 也是新 形势下应用型工科专业人才培养模式改革能否成功的关键因素。

关键词: 应用型工科, 创新能力, 校企合作, 就业能力

\section{1. 前言}

根据中国教育在线数据显示，2017年高校应届毕业生人数高达 795 万人，就业形势一年更 胜一年严峻 ${ }^{[1]}$ 。应用型工科专业的毕业生在择业过程中也遇到了前所未有的挑战。通过分析 毕业大学生的就业能力与用人企业的要求存在的差异得知, 创新能力不足已经成为影响大学 生就业和个人职业发展一个重要因素 ${ }^{[2]}$ ，在当前 “大众创业、万众创新” 背景下，如何改变 大学生的培养方式, 优化知识结构, 提升毕业生的实践能力和创新能力, 对于应用型工科专 业人才培养具有重要意义。

\section{2. 应用型工科专业大学生创新能力培养的意义}

创新是一个国家和民族永葆生机与活力, 永远立于不败之地的核心和关键, 是国家发展 和社会进步的强大动力。应用型工科专业的培养目标旨在培养适应社会信息化需求的、满足 企业研究、设计、制造、应用、开发和维护等需要的宽口径 “复合型” 高级工程技术人才, 不仅要具备扎实的专业知识, 同时还要具备快速适应工作岗位的工程实践能力、技术应用能 力和创新实践能力 ${ }^{[3]}$ 。因此, 创新能力的培养对于国家发展和高校育人都具有重要意义。 


\section{1 创新教育是国家建设发展的客观需要}

当今世界的竞争是国家创新能力的竞争, 是以培养创新型人才为宗旨的高等教育的竞争。 党的十八大明确提出实施创新驱动发展战略, 将其作为关系国民经济全局紧迫而重大的战略 任务。2015年李克强总理在政府工作报告中指出要把 “大众创业、万众创新” 打造成推动中 国经济前行的 “双引擎” 之一。大学生作为国家现代化建设的重要力量, 加强创新创业教 育, 提高创新创业能力, 是建设创新型国家的客观需要。

2.2 创新教育是高校提升办学质量的有效途径

近年来，随着高校办学条件和招生规模的不断扩大，每年的大学毕业生数量不断攀升， 2017年高校应届毕业生人数高达795万人，而面对如此庞大的就业人群，许多企业却抱怨招 聘不到需要的人才, 究其原因是高校的培养目标与企业需求脱节, 尤其是应用型工科专业的 毕业生不具备企业发展所必备的创新能力, 在当前以就业为导向的应用型培养目标下, 高校 如何制定合理的培养方案, 提升办学质量, 缓解就业压力, 对于高校发展和提升大学生就业 能力具有现实意义。

\section{3. 当前工科专业大学生创新能力培养存在的问题}

\section{1 创新意识淡薄, 缺乏正确奋斗目标}

职业方向是大学生职业生涯规划的首要问题，只有确定了发展方向才能制定出合理有效 的实施计划并付出努力 ${ }^{[4]}$ 。当前部分大学生在步入大学校园后, 认为学习不再是主要任务, 可以完全脱离之前的三点一线的生活, 有些甚至一直怀揣着进入大学后就可以不再学习的梦 想。有的学生仍保留大学以前的学习状态, 只注重书本上的知识, 追逐期末考试卷面的高成 绩, 而对一些课外活动、创新竞赛等漠不关心, 从自身学习目标方面就否定了创新意识的培 养。

而教师作为教育实践活动的组织者和实践者, 由于受到我国经济高速发展和企业生产技 术水平的明显提高的影响, 其知识结构有时不能够紧随市场发展潮流, 尤其是一些高新技术 产业，技术革新日新月异，教师的创新意识在学生创新能力培养上存在一定的不足。

\section{2 培养模式缺乏创新}

目前, 部分地方本科院校已经开展应用型本科培养模式, 但在人才培养方案和课程体系 上沿用学术型人才的培养模式, 不注意 “应用型” 技能的培养, 重理论、轻实践 ${ }^{[5]}$ 。而在授 课形式上, 学生仍是被动的学习方式, 理论课上教师讲解, 学生按部就班听讲, 缺乏良好的 互动和启发教学, 对于扩展内容学生表现毫无兴趣; 在实践教学上, 学生大都进行验证性实 验, 按照一成不变的实验讲义和电路, 进行重复性操作, 对于遇到的问题和优化设计等方面 内容缺乏认真思考, 导致学生的应试教育思想, 缺乏探索精神。

3.3 教学资源有待优化

应用型工科专业着重培养企业所需的人才，应用型人才所具备的创新能力应符合企业的 发展需要, 而目前部分高校所具备的教学资源与企业实际运行环境还有一定差距, 学生在学 校所学的技能和操作平台有时已经被企业所淘汰, 这势必影响学生的就业技能的提升, 脱离 了市场上所运行的技术平台且不了解企业的实际需要, 有时使得学生在创新培养上所取得的 成果并没有实际应用价值, 甚至出现盲目创新现象。

\section{4 提高应用型工科专业创新能力的有效途径}

4.1 充分发挥职业生涯规划课程体系作用, 做好引导

大学生职业生涯规划着重解决学生的职业方向问题, 只有确定了发展方向才能制定出合 理有效的实施计划并付出努力。合理的、有针对性大学生职业生涯规划教育可以让学生在学 习中认识自己, 了解当前的社会发展形势和企业的发展动态, 明确日后的就业方向, 及时调 整学习计划, 掌握核心技能, 提升就业能力, 最终实现就业目的, 良好的职业生涯规划课程 
体系可以改变学生盲目的学习状态, 分阶段及时引导学生掌握必要的知识技能, 进而为创新 能力的培养打下基础。

\section{2 开展启发式教学方式}

针对传统的授课方式, 应用型工科专业的培养应着重激发学生的自主学习能力, 只有学生 主动学习才能勤于思考, 才能遇到问题去想办法解决, 提高分析问题和解决问题的能力。教 师在整个教学过程中要做好身份的转变, 做好解惑的作用。对于课堂教学, 可采取分派学时, 让学生自主学习课本知识, 并充当教师完成授课任务, 即改掉了学生的学习惰性、调动了学 生的学习热情又提高了学生表达能力, 学生之间的问题探讨加深了对理论知识的理解, 教师 则作为评判仲裁的作用; 对于实践教学, 在学生完成必要的基础内容后, 可以灵活设置实践 项目, 鼓励学生利用实验室资源自主设置内容完成实验学时或开放式实验室项目, 调动学生 解决实际问题的学习动力。

\section{3 优化校企合作，资源共享}

校企合作是当前提高办学质量、提升大学生就业能力的有效手段之一，是应用型工科专业 学生创新能力提升的良好平台 ${ }^{[6]}$ 。应用型工科专业的人才培养应充分利用校企资源, 深化校企 合作模式，完善培养机制，打造多元化的教师队伍，加强教师到企业实习深造制度，提升教 师素质, 同时聘请企业工程师等为兼职人员, 担任职业生涯规划教育导师、或毕业论文导师, 力求教学团队学术背景合理化。切实加强学生企业实习制度, 企业见习、生产实习以及顶岗 实习等实习形式为学生提供了广阔的社会平台, 帮助学生认识社会、了解行业、大大激发学 生学习兴趣, 为应用型工科专业学生创新能力的培养提供坚实的平台。

\section{5 结论}

在当前严峻的就业形势下, 应用型工科专业学生的创新能力已经成为影响学生就业的重 要因素, 针对目前地方本科院校在应用型培养上存在着创新意识淡漠、缺乏正确的奋斗目 标, 培养模式缺乏创新和教学资源有待优化等问题, 应用型工科专业的培养模式应以深化校 企合作为基础, 充分利用学校和企业的优势资源, 完善职业生涯规划教育体制, 创新培养方 式, 充分调动学生的自主学习能力, 为应用型工科专业学生的创新能力提升提供良好的培养 机制。

\section{致谢}

黑龙江省教育科学规划课题省青年专项课题（资助号：GBD1213013）

\section{References}

[1]. Y.C.Li, "Investigation and Research on the employment ability of Undergraduates in the application oriented Universities," China Higher Education Research, vol.8,pp.67-69,2010.

[2]. C.Shu, "Research on improving the employment ability of electric information specialty application talents under the cooperation between school and enterprise, " International Conference on Management Science and Innovative Education. Wu Han, 2015.12, p. 216-219.

[3]. J. X. Zhang, "Analysis on the strategies of improving the students' high quality employment ability under the new situation," Heilongjiang Researches on Higher Education, vol.3, pp. 84-86, 2014.

[4]. B.R.Dai. Solutions to Alleviating the Employment Pressure of College Students. Theory and Practice of Education. Vol. 34 (2014) No. 18, p.3-5. 
[5]. H. Wang and M. L. He,"Cultivation of university students' employability based on the perspective of market demand orientation," Logistics Engineering and Management, vol.3, pp. 230-235, 2012.

[6]. C.Shu,J.S.Mei, J.Y.Yang,Y.Sun,X.X.Chen, "Research on career planning education for college students of applied electric specialty,” International Conference on Management Science and Innovative Education. Wu Han, 2016.5, p.172-175 